Case Report

\title{
Amiodarone-Induced Thyrotoxic Thyroiditis: A Diagnostic and Therapeutic Challenge
}

\author{
Umang Barvalia, ${ }^{1}$ Barkha Amlani, ${ }^{1}$ and Ram Pathak ${ }^{2}$ \\ ${ }^{1}$ Department of Internal Medicine, Marshfield Clinic, 1000 N. Oak Avenue, Marshfield, WI 54449, USA \\ ${ }^{2}$ Department of Endocrinology, Marshfield Clinic, Marshfield, WI 54449, USA
}

Correspondence should be addressed to Umang Barvalia; barvalia.umang@gmail.com

Received 16 September 2014; Accepted 23 October 2014; Published 12 November 2014

Academic Editor: Grigorios Korosoglou

Copyright (C) 2014 Umang Barvalia et al. This is an open access article distributed under the Creative Commons Attribution License, which permits unrestricted use, distribution, and reproduction in any medium, provided the original work is properly cited.

\begin{abstract}
Amiodarone is an iodine-based, potent antiarrhythmic drug bearing a structural resemblance to thyroxine (T4). It is known to produce thyroid abnormalities ranging from abnormal thyroid function testing to overt hypothyroidism or hyperthyroidism. These adverse effects may occur in patients with or without preexisting thyroid disease. Amiodarone-induced thyrotoxicosis (AIT) is a clinically recognized condition commonly due to iodine-induced excessive synthesis of thyroid, also known as type 1 AIT. In rare instances, AIT is caused by amiodarone-induced inflammation of thyroid tissue, resulting in release of preformed thyroid hormones and a hyperthyroid state, known as type 2 AIT. Distinguishing between the two states is important, as both conditions have different treatment implications; however, a mixed presentation is not uncommon, posing diagnostic and treatment challenges. We describe a case of a patient with amiodarone-induced type 2 hyperthyroidism and review the current literature on the best practices for diagnostic and treatment approaches.
\end{abstract}

\section{Introduction}

Amiodarone is a potent antiarrhythmic drug used in the treatment of various ventricular and supraventricular arrhythmias. It carries a structural resemblance to thyroxine (T4) and can produce a wide spectrum of thyroid gland dysfunctions. Amiodarone-induced thyrotoxicosis (AIT) is commonly due to iodine-induced excessive synthesis of thyroid, also known as type 1 AIT (AIT1). However, in rare instances, AIT is due to amiodarone-induced inflammation of the thyroid tissue resulting in release of preformed thyroid hormones or a hyperthyroid state, known as type 2 AIT (AIT2). Due to incomplete understanding of the pathogenesis, unreliable response to therapy, and lack of a systemic approach, AIT2 continues to challenge the clinical acumen of internists and endocrinologists. Besides thyroid function testing, ultrasonography, radioiodine uptake and scan, interleukin-6 (IL-6) level determination, and color flow Doppler sonography (CFDS) aid in diagnosis and assessing the response of AIT2 to therapy. Use of $99 \mathrm{mTc}$-sestamibi (MIBI) scanning is emerging as a beneficial adjunct to diagnosis. The current literature still supports steroids as the mainstay for treatment of AIT2. Iopanoic acid and perchlorate are reasonable therapeutic options but have not been shown to provide benefit when used with steroids. Close monitoring is essential, as the onset of AIT2 has been found to be a predictor of adverse cardiovascular outcomes [1].

\section{Case Presentation}

A 63-year-old man had been on amiodarone therapy $200 \mathrm{mg} /$ day for approximately 2 years for recurrent angina pain secondary to paroxysmal atrial fibrillation despite control of ventricular rate. He was referred to the endocrinology department for concerns of hyperthyroidism diagnosed during routine follow-up of thyroid function monitoring related to his exposure to amiodarone. He reported a 19pound weight loss in the past year, some of it intentional, and worsening of a hand tremor that he had for years. He denied any other symptoms of hyperthyroidism.

The past medical history was significant for nonocclusive coronary artery disease, hypertension, morbid obesity, and 


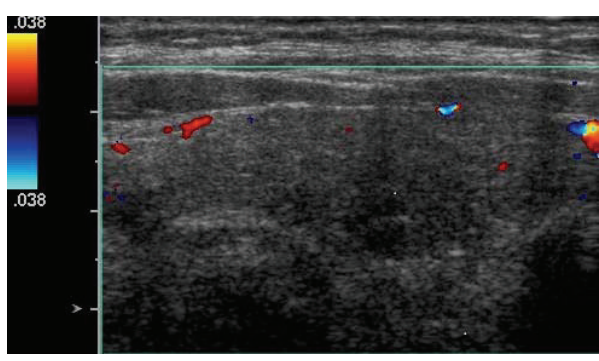

(a)

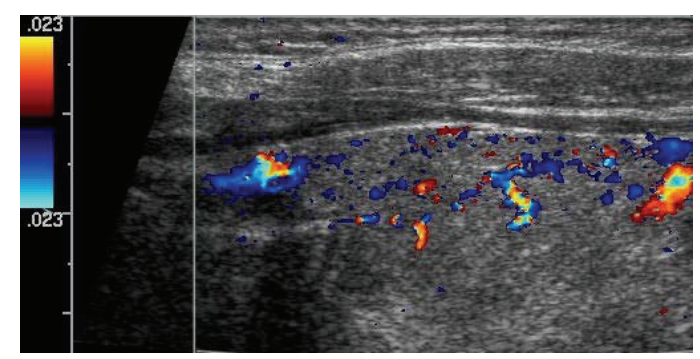

(b)

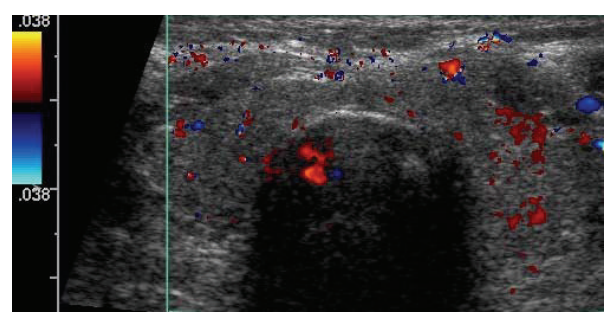

(c)

FIgure 1: Thyroid ultrasound with color Doppler flow study showing normal to minimally reduced vascularity of the glandular tissue. (a) Long axis view of the right thyroid lobe. (b) Long axis view of the left thyroid lobe. (c) Transverse axis view of both lobes of thyroid gland including the isthmus.

peripheral vascular disease with claudication. His family history included a sister with thyroid-related symptomology, but he was not able to provide further details. The patient was alert, in no acute distress, with a body weight of 263 pounds. Examination of the thyroid gland did not reveal palpable nodules on either lobe. The gland moved freely during swallowing and was somewhat diffusely enlarged. No lymphadenopathy or tenderness was noted on palpation. Vital signs were normal with a blood pressure of $110 / 60 \mathrm{~mm} \mathrm{Hg}$. The remainder of the examination was unremarkable.

Thyroid function tests revealed a thyroid stimulating hormone (TSH) level of $0.01 \mathrm{mIU} / \mathrm{mL}$ (range $0.35-4.5 \mathrm{mIU} / \mathrm{mL}$ ), free T4 of $2.7 \mathrm{ng} / \mathrm{dL}$ (range $0.6-1.2 \mathrm{ng} / \mathrm{dL}$ ), and free T3 levels of $3.7 \mathrm{pg} / \mathrm{mL}$ (range $2.1-4.1 \mathrm{pg} / \mathrm{mL}$ ). Thyroid ultrasound did not show hypervascularity (Figure 1). An ultrasound done 2 years previously had revealed a multinodular gland with a dominant right-sided $1.3 \times 0.8 \mathrm{~cm}$ nodule that was found to be benign on fine needle aspiration biopsy. There was another $1.1 \times 0.6 \mathrm{~cm}$ nodule on the left side that was not biopsied. The right-sided dominant nodule remained stable, and the left-side nodule had slightly increased to $1.2 \mathrm{~cm}$ in size. Radioiodine uptake and scan had $0.6 \%$ (range 4-20\%) and $0.2 \%$ (range $5-30 \%$ ) uptake at 4 hours and 24 hours, respectively, consistent with amiodarone-induced thyrotoxicosis in the clinical context (Figure 2). Screening for thyroglobulin antibody was normal at $<20 \mathrm{IU} / \mathrm{mL}$. The thyroglobulin level was $22.6 \mathrm{ng} / \mathrm{mL}$, and IL-6 level was elevated at $8.63 \mathrm{pg} / \mathrm{mL}$ (range $0.31-5 \mathrm{pg} / \mathrm{mL}$ ).

Although none of the findings were diagnostic, they favored a diagnosis of AIT2, more so than the more common AIT1. The patient was treated with low-dose steroids $(20 \mathrm{mg}$ prednisone daily) for a month with deescalation of dosing following improvement in thyroid function tests. He reported improvement in the bilateral hand tremor, back to his

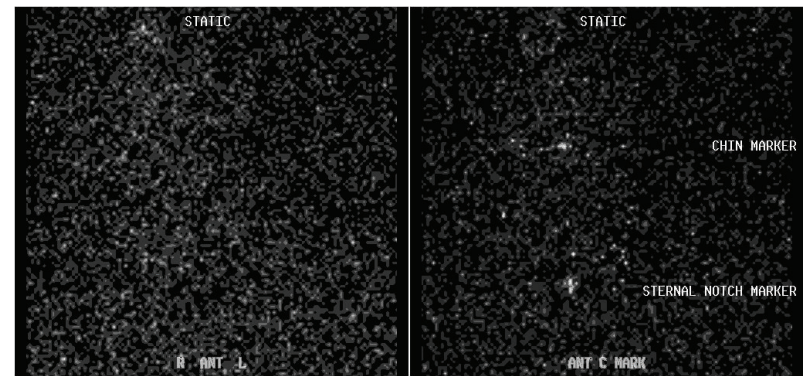

FIGURE 2: Radioiodine uptake and scan using $143 \mu \mathrm{Ci}$ of I-123 showing $0.6 \%$ uptake at 4 hours (no activity within the thyroid gland).

baseline, and was euthyroid with TSH of $3.09 \mathrm{mIU} / \mathrm{mL}$, free $\mathrm{T} 4 \mathrm{of} 1.0 \mathrm{ng} / \mathrm{dL}$, and free T3 of $2.5 \mathrm{pg} / \mathrm{mL}$ during subsequent follow-up 3 months later. The patient remained euthyroid clinically and biochemically without recurrence of AIT, while continuing amiodarone therapy for 3 years following treatment of the AIT2.

\section{Discussion}

Amiodarone is used in treating various atrial and ventricular arrhythmias and is favored in patients with left ventricular dysfunction [2]. Due to the structural similarity with thyroid hormones and the iodine content in the medication, it is known to cause significant changes in thyroid function testing, often with a clinically significant impact [3].

3.1. Mechanisms of Amiodarone-Related Thyroid Dysfunction. Amiodarone inhibits type $15^{\prime}$-deiodinase activity in the liver/peripheral tissues, which may persist for weeks 
TABLE 1: Effects of amiodarone on thyroid function tests in euthyroid patients.

\begin{tabular}{lll}
\hline Test & \multicolumn{2}{c}{ Duration of treatment } \\
& Subacute $(<3$ months $)$ & Chronic ( $>3$ months $)$ \\
\hline T4 & Modest increase & $\begin{array}{l}\text { Remains increased by up to } \\
40 \% \text { above baseline; may be } \\
\text { in high reference range or } \\
\text { moderately raised }\end{array}$ \\
& Decreased, usually to low & $\begin{array}{l}\text { Remains in low reference } \\
\text { range or slightly low }\end{array}$ \\
T3 & reference range & $\begin{array}{l}\text { Normal, but there may be } \\
\text { periods of high or low } \\
\text { values }\end{array}$ \\
TSH & $\begin{array}{l}\text { Transient increase } \\
\text { (up to 20 mU/L) }\end{array}$ & Increased \\
\hline rT3 & Increased &
\end{tabular}

Used with permission from Heart (Newman et al. 1998 [3]).

following withdrawal of the drug [4]. Further, the drug inhibits type $25^{\prime}$-deiodinase activity in the pituitary, which reduces conversion of T4 to T3 and increased TSH levels [5]. Whereas amiodarone has no effect on the metabolism (distribution and removal) of plasma T3 pool [6], the drug does inhibit thyroid hormone entry into circulation [7]. Table 1 summarizes the effects of amiodarone on thyroid function tests in euthyroid patients.

Due to its intrinsic properties, amiodarone is associated more with hypothyroidism than thyrotoxicosis in iodine replete countries like the United Kingdom and the United States [8]. Pathogenesis of amiodarone-induced hyperthyroidism is still incompletely understood, which makes the diagnosis and treatment challenging. Two main types of AIT, with different mechanisms, have been described. AIT1 is due to iodine-induced excess synthesis and release of thyroid hormones, usually from abnormal thyroid glands. AIT2 is a form of destructive thyroiditis that leads to leakage of preformed hormones into the circulation. Though iodine excess may be an important pathogenic factor in both subtypes, some forms of AIT may be purely due to subacute thyroiditis and release of preformed hormones.

3.2. Diagnoses of AIT2. AIT usually has a sudden onset, presenting with a new or worsening arrhythmia, or it can be asymptomatic, especially in younger individuals $[9,10]$. Because type 1 hyperthyroidism often occurs in patients with preexisting thyroid disease, the onset is within the first few months, whereas median time for occurrence of AIT2 is about 30 months following initiation of amiodarone therapy [11]. In either case, the initial evaluation should include the usual work-up for thyroid function including TSH, T3, T4, and antithyroid antibodies. Thyroid ultrasound with or without CFDS and radioiodine uptake (RAIU) and scan are useful in distinguishing the two AIT subtypes.

In AIT2, RAIU would be lower $(<1 \%)$ compared to AIT1, where it is either normal or increased $(>10 \%)$ [12]. In the United States, where most patients are iodine replete, RAIU can be low in both types of AIT, so CFDS is helpful in directing therapy $[13,14]$. CFDS gives real time information
TABLE 2: ${ }^{*}$ Clinical and pathologic features distinguishing type 1 and type 2 amiodarone-induced hyperthyroidism ${ }^{\dagger}$.

\begin{tabular}{|c|c|c|}
\hline & Type 1 & Type 2 \\
\hline $\begin{array}{l}\text { Underlying } \\
\text { thyroid disease }\end{array}$ & Yes & No \\
\hline $\begin{array}{l}\text { Thyroid } \\
\text { ultrasound }\end{array}$ & $\begin{array}{l}\text { Diffuse or nodular } \\
\text { goiter }\end{array}$ & $\begin{array}{l}\text { Normal (hypoechoic) } \\
\text { gland (small goiter) }\end{array}$ \\
\hline CFDS & Increased vascularity & $\begin{array}{l}\text { Normal to reduced } \\
\text { vascularity }\end{array}$ \\
\hline Thyroid RAIU & Low/normal/increased & Low/absent \\
\hline MIBI & Thyroid retention & Absent uptake \\
\hline Pathogenesis & $\begin{array}{l}\text { Iodine-induced } \\
\text { hyperthyroidism }\end{array}$ & $\begin{array}{l}\text { Destructive } \\
\text { thyroiditis }\end{array}$ \\
\hline $\begin{array}{l}\text { Spontaneous } \\
\text { remission }\end{array}$ & No & Possible \\
\hline $\begin{array}{l}\text { Preferred } \\
\text { treatment }\end{array}$ & $\begin{array}{l}\text { Thionamides } \\
\text { (plus perchlorate) }\end{array}$ & Glucocorticoids \\
\hline $\begin{array}{l}\text { Posttherapy } \\
\text { hypothyroidism }\end{array}$ & Unlikely & Possible \\
\hline
\end{tabular}

${ }^{*}$ Modified from Table 1, Bogazzi et al. [12].

${ }^{\dagger}$ Mixed forms of AIT have not been fully understood and are believed to be a combination of iodine-induced hyperthyroidism and destructive thyroiditis from the drug itself.

CFDS: color flow Doppler sonography; RAIU: radioiodine uptake; MIBI: 99mTc-sestamibi.

on the blood flow inside the thyroid gland and its morphology. Due to follicular destruction, lymphocyte infiltration consequential to inflammatory responses seen in AIT2, the color flow on ultrasound would show increased vascularity and blood flow velocity [15]. These findings are indicative of a hyperfunctioning gland and are also seen in untreated Grave's disease. CFDS can serve to facilitate decision making due to its relative ease of use, ability to obtain faster results, and the noninvasive nature of the study, especially in patients with life-threatening tachyarrhythmias.

MIBI scanning has been used for detection of hyperfunctioning parathyroid adenomas and some malignant or benign thyroid tumors. There has been recent interest in its use in distinguishing between the two types of AIT. A small study of 20 patients found that it was superior to CFDS in differentiating between AIT1 and AIT2 [16].

Interleukin-6 (IL-6), a cytokine associated with inflammation, was proposed as a biomarker to distinguish between amiodarone-induced thyroiditis and iodine-induced hyperthyroidism. Marked elevations of IL-6 levels correlated closely with subacute thyroiditis in patients without preexisting thyroid disease. Normal to mild elevations of IL-6 were also found in patients with AIT1 [17]. Table 2 presents a comparative summary between the two types of amiodaroneinduced hyperthyroidism.

3.3. Treatment. The best available treatment option for AIT2 is oral glucocorticoids. They act by reducing the inflammation in the thyroid gland, the primary pathologic mechanism in AIT2, and also reduce the peripheral conversion of T4 to T3 [18]. Baseline free T4 concentrations and thyroid gland volume can predict delayed responders to glucocorticoids. 
In individuals at high risk, this may help identify individuals in whom surgery and/or iopanoic acid should be considered early in the course of the disease [19].

Iopanoic acid, an oral cholecystographic agent (OCA), acts by inhibiting type $15^{\prime}$-deiodinase activity, the enzyme responsible for peripheral conversion of T4 to T3. A 70\% reduction of serum T3 levels was observed after $48 \mathrm{~h}$ of iopanoic acid administration in spontaneous hyperthyroid patients, with little effect on serum T4 concentration. However, iopanoic acid does not affect the destructive thyroiditis processes associated with AIT2 [20]. Iopanoic acid is a reasonable alternative to steroids to control hyperthyroidism in the short term, but it would take longer than the use of steroids in achieving the euthyroid state, as shown in a small, prospective, randomized control trial [21].

Due to coexistence of both forms of AIT, there is often a variable response to glucocorticoid therapy in AIT2. Thionamides are sometimes needed in addition to glucocorticoids to achieve euthyroid status in these patients. IL-6 levels can aid in choosing therapy, but it may take days to weeks for the levels to be reported. Therefore, in severely ill patients, until the diagnosis is certain, it is prudent to treat both AIT1 and AIT2 with antithyroid drugs and glucocorticoids with or without perchlorate. Thyroidologists may employ a stepwise approach, where initial therapy would constitute using thionamides for 4 weeks and introduce steroids if there is insufficient or no response to thionamide therapy [22].

Guitierrez-Repiso et al. [23] observed that, in an adult population with adequate and stable nutrition, the iodine excretion in a random urine sample represented $70-80 \%$ of the daily iodine intake. This fact was also utilized by several investigators for either diagnosis or treatment of druginduced thyrotoxicosis [24-26]. Erdoğan and colleagues suggested treating AIT with prednisone, potassium perchlorate, and titrating methimazole using urinary iodine excretion [27].

The majority of thyroidologists in North America and Europe did not recommend measuring urinary iodine for management of AIT. Urinary iodine excretion would not be an ideal marker of individual iodine nutrition because of the intraindividual variability considering changes in dietary iodine intake and thyroid function [23]. In cases of recurrent, refractory, or mixed forms of AIT where euthyroid status is not achieved with steroids alone, monitoring monthly levels and continuing steroids or adding methimazole until urine iodine concentration normalizes $(<200 \mu \mathrm{g} /$ day $)$ might be reasonable.

Amiodarone and its derivative desethylamiodarone have a long half-life of 40 and 57 days, respectively, due to the lipophilic nature of the drug and subsequent concentration in various tissues including adipose tissue [28]. Hence, withdrawal of the drug should not have immediate beneficial effects. It remains unclear whether amiodarone should be continued after diagnosis. There have been instances of amiodarone-induced coronary vasospasm and ischemic ventricular fibrillation related to hyperthyroid states [29]. Bogazzi et al. showed that the drug delays restoration of euthyroid status, and there are higher chances of recurrence when amiodarone is continued [20]. Euthyroid states were still achieved with continuation of amiodarone [30]. Consequently, decisions must be made on a case-by-case basis, and the drug should be withdrawn only if it is not too risky for the patient.

Measurement of iodine uptake and/or urine iodine excretion can be done to make sure that the iodine load has resolved. In surveys, after restoration of euthyroidism and withdrawal of amiodarone, thyroid ablation was selected less frequently by North American thyroidologists in AIT1, while an expectant strategy was shared by both North Americans and Europeans in AIT2 [31-33]. If amiodarone therapy needs to be reinitiated, prophylactic RAI therapy or thyroidectomy was recommended in AIT1; "wait and watch" strategy was still adopted for majority of the patients with AIT2, unless there was a relapse [31-33].

Subtotal or total thyroidectomy may be needed in cases of AIT that progresses despite aggressive medical therapy, especially in critically ill patients in whom discontinuing amiodarone can be life threatening. In patients with AIT and left ventricular systolic dysfunction, left ventricular ejection fraction improved when they underwent total thyroidectomy following failure to achieve euthyroid state with optimal medical treatment [34]. Several case reports have been published on treatment with lithium, plasmapheresis, and/or methimazole in refractory cases [35-37]. Perchlorate was hypothesized to ameliorate the cytotoxic side effects of amiodarone on thyrocytes and thereby help in restoration of euthyroid status when a mixed type of AIT was suspected. A multicenter randomized control in Netherlands showed that perchlorate, when used alone or in combination with prednisone, did not improve outcomes [30]. AIT patients generally have low RAIU values, and radioiodine ablation might not be feasible; however, an open study showed that it might be an option even in those patients [38]. Using recombinant $\mathrm{TSH}$ to allow radioiodine as a treatment modality has been proposed; however, subsequent elevation of thyroid hormone levels could potentially worsen underlying cardiac problems in these patients [39].

It is important to follow up patient's status with thyroid function testing, even after restoration to euthyroid state, as they may develop temporary or permanent hypothyroidism and may subsequently benefit from hormone replacement therapy [40].

\section{Conclusion}

Amiodarone-induced hyperthyroidism still remains a diagnostic challenge due to its incompletely understood pathogenesis, unreliable response to therapy, and lack of systemic approach. Steroids are the mainstay for treatment of AIT2. IL6 levels and CFDS may be helpful in aiding with diagnosis and assessing response to therapy. Surgery should be considered on a case-by-case basis in patients with uncontrolled hyperthyroidism with conservative measures or in whom watchful medical management could have deleterious effects. In case of progressive deterioration, where restoration of euthyroid status is essential, a short course of iopanoic acid followed by surgical removal of the gland should be considered. Lithium, plasmapheresis, and radioactive treatment have 
been attempted, but there is currently limited evidence to recommend their use.

\section{Disclosure}

A poster of this case report was presented at the annual meeting of the American Thyroid Association.

\section{Conflict of Interests}

The authors declare that there is no conflict of interests regarding the publication of this paper.

\section{References}

[1] K.-H. Yiu, M.-H. Jim, C.-W. Siu et al., "Amiodarone-induced thyrotoxicosis is a predictor of adverse cardiovascular outcome," Journal of Clinical Endocrinology and Metabolism, vol. 94, no. 1, pp. 109-114, 2009.

[2] D. G. Julian, A. J. Camm, G. Frangin et al., "Randomised trial of effect of amiodarone on mortality in patients with left-ventricular dysfunction after recent myocardial infarction: EMIAT," The Lancet, vol. 349, no. 9053, pp. 667-674, 1997.

[3] C. M. Newman, A. Price, D. W. Davies, T. A. Gray, and A. P. Weetman, "Amiodarone and the thyroid: a practical guide to the management of thyroid dysfunction induced by amiodarone therapy," Heart, vol. 79, no. 2, pp. 121-127, 1998.

[4] S. Aanderud, J. Sundsfjord, and J. Aarbakke, "Amiodarone inhibits the conversion of thyroxine to triiodothyronine in isolated rat hepatocytes," Endocrinology, vol. 115, no. 4, pp. 16051608, 1984.

[5] M. Safran, S.-L. Fang, G. Bambini, A. Pinchera, E. Martino, and L. E. Braverman, "Effects of amiodarone and desethylamiodarone on pituitary deiodinase activity and thyrotropin secretion in the rat," American Journal of the Medical Sciences, vol. 292, no. 3, pp. 136-141, 1986.

[6] A. Zaninovich, S. Bosco, and A. Fernandez-Pol, "Amiodarone does not affect the distribution and fractional turnover of triiodothyronine from the plasma pool, but only its generation from thyroxine in extrathyroidal tissues," The Journal of Clinical Endocrinology \& Metabolism, vol. 70, no. 6, pp. 1721-1724, 1990.

[7] E. P. Krenning, R. Docter, B. Bernard, T. Visser, and G. Hennemann, "Decreased transport of thyroxine (T4), 3,3'-5triiodothyronine (T3) and 3,3',5' -triiodothyronine (rT3) into rat hepatocytes in primary culture due to a decrease of cellular ATP content and various drugs," FEBS Letters, vol. 140, no. 2, pp. 229-233, 1982.

[8] E. Martino, F. Aghini-Lombardi, S. Mariotti, L. Bartalena, L. Braverman, and A. Pinchera, "Amiodarone: a common source of iodine-induced thyrotoxicosis," Hormone Research, vol. 26, no. 1-4, pp. 158-171, 1987.

[9] S. Basaria and D. S. Cooper, "Amiodarone and the thyroid," The American Journal of Medicine, vol. 118, no. 7, pp. 706-714, 2005.

[10] J. Cohen-Lehman, P. Dahl, S. Danzi, and I. Klein, "Effects of amiodarone therapy on thyroid function," Nature Reviews Endocrinology, vol. 6, no. 1, pp. 34-41, 2010.

[11] L. Tomisti, G. Rossi, L. Bartalena, E. Martino, and F. Bogazzi, "The onset time of amiodarone -induced thyrotoxicosis (AIT) depends on AIT type," European Journal of Endocrinology, vol. 171, no. 3, Article ID 363368, pp. 363-368, 2014.
[12] F. Bogazzi, L. Bartalena, and E. Martino, "Approach to the patient with amiodarone-induced thyrotoxicosis," Journal of Clinical Endocrinology and Metabolism, vol. 95, no. 6, pp. 25292535, 2010.

[13] F. Bogazzi, E. Martino, E. Dell'Unto et al., “Thyroid color flow doppler sonography and radioiodine uptake in 55 consecutive patients with amiodarone-induced thyrotoxicosis," Journal of Endocrinological Investigation, vol. 26, no. 7, pp. 635-640, 2003.

[14] F. Bogazzi, L. Bartalena, S. Brogioni et al., "Color flow doppler sonography rapidly differentiates type I and type II amiodarone-induced thyrotoxicosis," Thyroid, vol. 7, no. 4, pp. 541-545, 1997.

[15] M. Loy, E. Perra, A. Melis et al., "Color-flow doppler sonography in the differential diagnosis and management of amiodaroneinduced thyrotoxicosis," Acta Radiologica, vol. 48, no. 6, pp. 628-634, 2007.

[16] M. Piga, M. C. Cocco, A. Serra, F. Boi, M. Loy, and S. Mariotti, "The usefulness of $99 \mathrm{mTc}$-sestaMIBI thyroid scan in the differential diagnosis and management of amiodaroneinduced thyrotoxicosis," European Journal of Endocrinology, vol. 159, no. 4, pp. 423-429, 2008.

[17] L. Bartalena, S. Brogioni, L. Grasso et al., "Interleukin-6: a marker of thyroid-destructive processes?" Journal of Clinical Endocrinology and Metabolism, vol. 79, no. 5, pp. 1424-1427, 1994.

[18] L. Bartalena, S. Brogioni, L. Grasso, F. Bogazzi, A. Burelli, and E. Martino, "Treatment of amiodarone-induced thyrotoxicosis, a difficult challenge: results of a prospective study," Journal of Clinical Endocrinology and Metabolism, vol. 81, no. 8, pp. 29302933, 1996.

[19] F. Bogazzi, L. Bartalena, L. Tomisti et al., "Glucocorticoid response in amiodarone-induced thyrotoxicosis resulting from destructive thyroiditis is predicted by thyroid volume and serum free thyroid hormone concentrations," Journal of Clinical Endocrinology and Metabolism, vol. 92, no. 2, pp. 556-562, 2007.

[20] F. Bogazzi, L. Bartalena, L. Tomisti, G. Rossi, S. Brogioni, and E. Martino, "Continuation of amiodarone delays restoration of euthyroidism in patients with type 2 amiodarone-induced thyrotoxicosis treated with prednisone: a pilot study," The Journal of Clinical Endocrinology \& Metabolism, vol. 96, no. 11, pp. 3374-3380, 2011.

[21] F. Bogazzi, L. Bartalena, C. Cosci et al., "Treatment of type II amiodarone-induced thyrotoxicosis by either iopanoic acid or glucocorticoids: a prospective, randomized study," Journal of Clinical Endocrinology and Metabolism, vol. 88, no. 5, pp. 19992002, 2003.

[22] F. Bogazzi, L. Tomisti, G. Rossi et al., "Glucocorticoids are preferable to thionamides as first-line treatment for amiodarone-induced thyrotoxicosis due to destructive thyroiditis: a matched retrospective cohort study," Journal of Clinical Endocrinology and Metabolism, vol. 94, no. 10, pp. 3757-3762, 2009.

[23] C. Guitierrez-Repiso, N. Colomo, G. Rojo-Martinez et al., "Evolution of urinary iodine excretion over eleven years in an adult population," Clinical Nutrition, 2014.

[24] R. H. Rao, V. R. McCready, and G. S. Spathis, "Iodine kinetic studies during amiodarone treatment," Journal of Clinical Endocrinology and Metabolism, vol. 62, no. 3, pp. 563-568, 1986.

[25] A. Stankiewicz, M. Siekierzyński, and J. Wierzbowska, "Influence of topically apllied iodides on urinary iodine excretion and thyroid function," Klinika Oczna, vol. 105, no. 3-4, pp. 129-131, 2003 (Polish). 
[26] M. Pepe, F. M. Graziano, P. Di Perna, G. Salvati, and G. Reda, "Determination of iodine urinary excretion in cordarone induced hyperthyroidism," Clinica Terapeutica, vol. 148, no. 1-2, pp. 33-39, 1997 (Italian).

[27] M. F. Erdoğan, S. Güleç, E. Tutar, N. Başkal, and G. Erdoğan, "A stepwise approach to the treatment of amiodarone-induced thyrotoxicosis," Thyroid, vol. 13, no. 2, pp. 205-209, 2003.

[28] E. Martino, L. Bartalena, F. Bogazzi, and L. E. Braverman, “The effects of amiodarone on the thyroid," Endocrine Reviews, vol. 22, no. 2, pp. 240-254, 2001.

[29] M. J. Brooks, D. A. Pattison, E. P. Teo, S. Price, and R. Gurvitch, "Amiodarone-induced destructive thyroiditis associated with coronary artery vasospasm and recurrent ventricular fibrillation," European Thyroid Journal, vol. 2, no. 1, pp. 65-67, 2013.

[30] S. A. Eskes, E. Endert, E. Fliers et al., "Treatment of amiodaroneinduced thyrotoxicosis type 2: a randomized clinical trial," The Journal of Clinical Endocrinology \& Metabolism, vol. 97, no. 2, pp. 499-506, 2012.

[31] L. Bartalena, W. M. Wiersinga, M. L. Tanda et al., "Diagnosis and management of amiodarone-induced thyrotoxicosis in Europe: results of an international survey among members of the European Thyroid Association," Clinical Endocrinology, vol. 61, no. 4, pp. 494-502, 2004.

[32] L. A. Diehl, J. H. Romaldini, H. Graf et al., "Management of amiodarone-induced thyrotoxicosis in Latin America: an electronic survey," Clinical Endocrinology, vol. 65, no. 4, pp. 433438, 2006.

[33] M. L. Tanda, E. Piantanida, A. Lai et al., "Diagnosis and management of amiodarone-induced thyrotoxicosis: similarities and differences between North American and European thyroidologists," Clinical Endocrinology, vol. 69, no. 5, pp. 812$818,2008$.

[34] L. Tomisti, G. Materazzi, L. Bartalena et al., "Total thyroidectomy in patients with amiodarone-induced thyrotoxicosis and severe left ventricular systolic dysfunction," Journal of Clinical Endocrinology and Metabolism, vol. 97, no. 10, pp. 3515-3521, 2012.

[35] G. Dickstein, C. Shechner, F. Adawi, J. Kaplan, E. Baron, and S. Ish-Shalom, "Lithium treatment in amiodarone-induced thyrotoxicosis," The American Journal of Medicine, vol. 102, no. 5, pp. 454-458, 1997.

[36] Y. Erbil, D. Tihan, A. Azezli et al., "Severe hyperthyroidism requiring therapeutic plasmapheresis in a patient with hydatidiform mole," Gynecological Endocrinology, vol. 22, no. 7, pp. 402404, 2006.

[37] F. Aghini-Lombardi, S. Mariotti, P. V. Fosella et al., "Treatment of amiodarone iodine-induced thyrotoxicosis with plasmapheresis and methimazole," Journal of Endocrinological Investigation, vol. 16, no. 10, pp. 823-826, 1993.

[38] A. Czarnywojtek, R. Czepczynski, M. Ruchala et al., "Radioiodine therapy in patients with amiodarone-induced thyrotoxicosis (AIT)," Neuroendocrinology Letters, vol. 30, no. 2, pp. 209214, 2009.

[39] F. Bogazzi, L. Tomisti, C. Ceccarelli, and E. Martino, "Recombinant human TSH as an adjuvant to radioiodine for the treatment of type 1 amiodarone-induced thyrotoxicosis: a cautionary note," Clinical Endocrinology, vol. 72, no. 1, pp. 133-134, 2010.

[40] E. Roti, R. Minelli, E. Gardini, L. Bianconi, and L. E. Braverman, "Thyrotoxicosis followed by hypothyroidism in patients treated with amiodarone: a possible consequence of a destructive process in the thyroid," Archives of Internal Medicine, vol. 153, no. 7, pp. 886-892, 1993. 


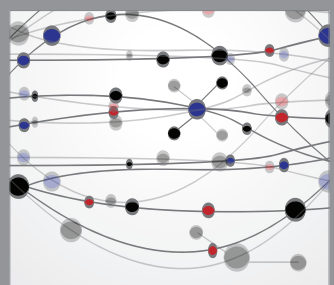

The Scientific World Journal
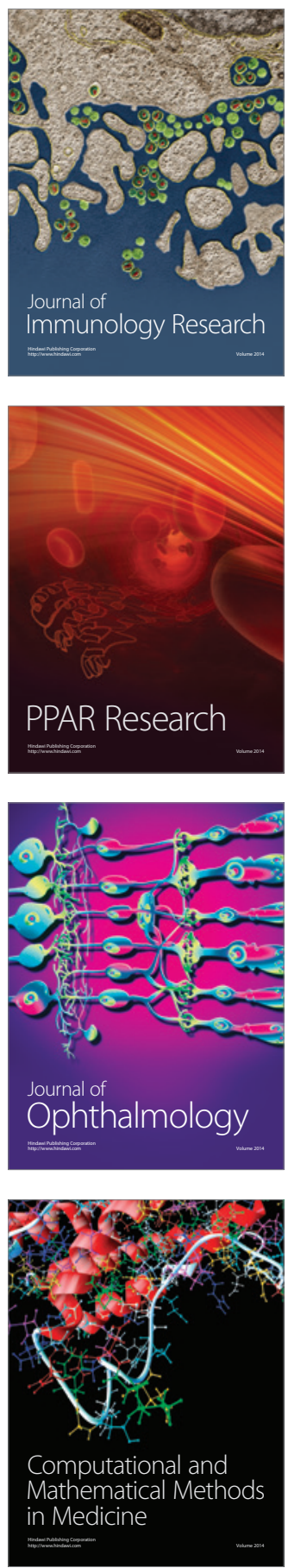

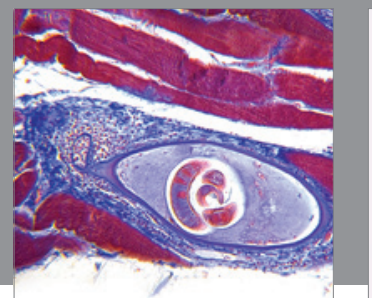

Gastroenterology

Research and Practice
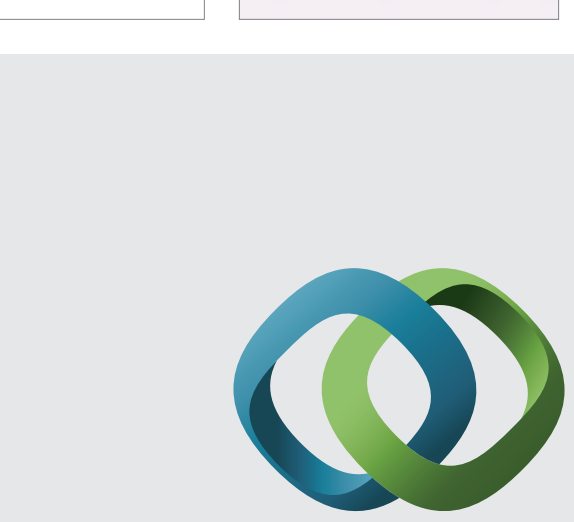

\section{Hindawi}

Submit your manuscripts at

http://www.hindawi.com
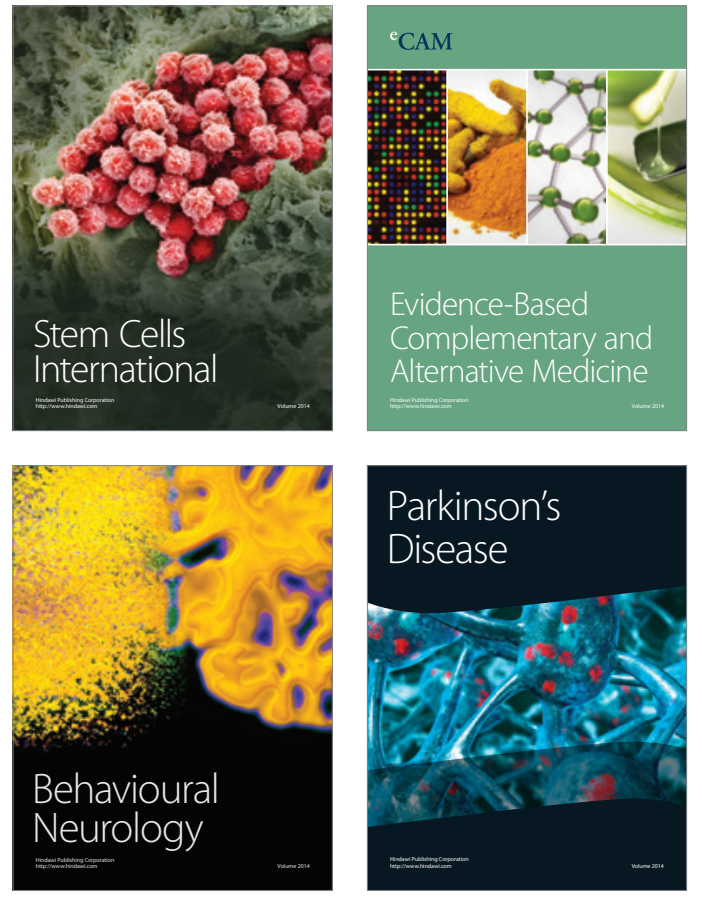
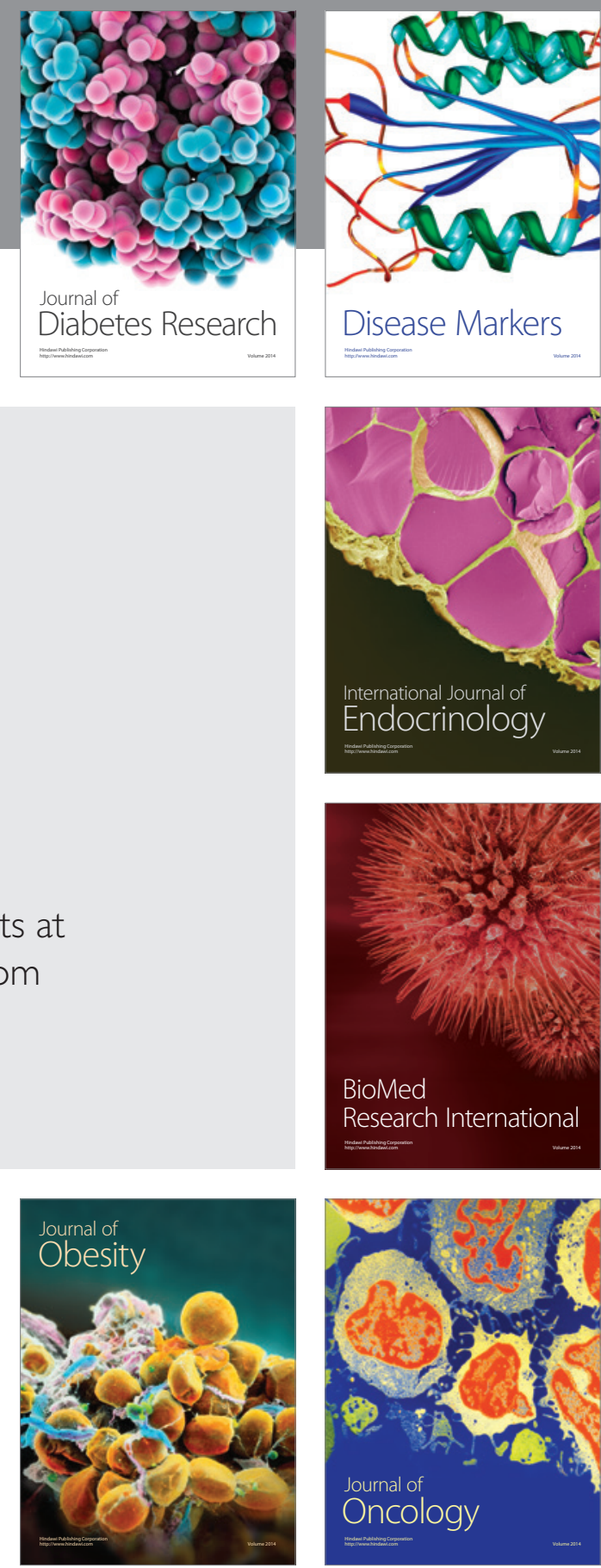

Disease Markers
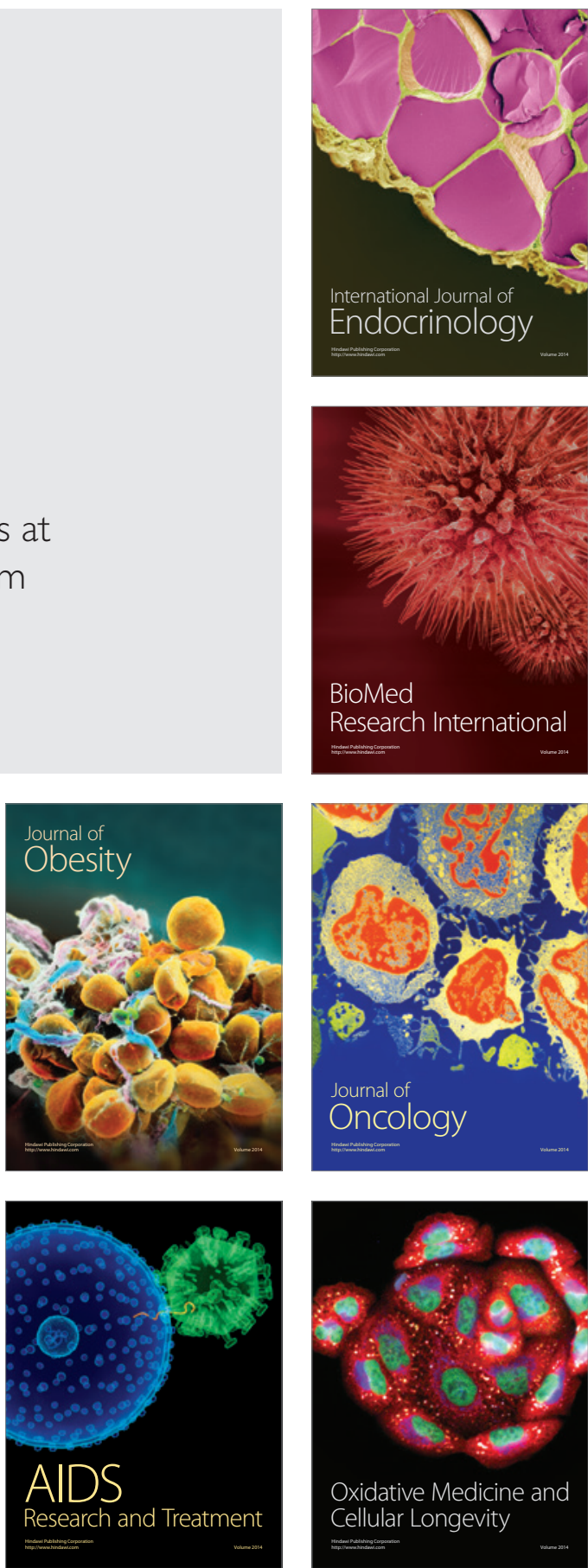